\title{
Lung Cancer in Women with a Family History of Cancer: The Spanish Female-specific Database WORLD07
}

\author{
DOLORES ISLA $^{1}$, ENRIQUETA FELIP ${ }^{2}$, NURIA VIÑOLAS $^{3}$, MARIANO PROVENCIO $^{4}$, MARGARITA MAJEM $^{5}$, \\ ANGEL ARTAL ${ }^{6}$, ISABEL BOVER ${ }^{7}$, PILAR LIANES $^{8}$, RAMÓN DE LAS PEÑAS $^{9}$, SILVIA CATOT $^{10}$, \\ JAVIER DE CASTRO ${ }^{11}$, ANA BLASCO ${ }^{12}$, JOSEFA TERRASA ${ }^{13}$, JOSÉ LUIS GONZALEZ-LARRIBA ${ }^{14}$, \\ OSCAR JUAN $^{15}$, MANUEL DÓMINE ${ }^{16}$, REYES BERNABE ${ }^{17}$ and PILAR GARRIDO ${ }^{18}$ \\ ${ }^{1}$ Medical Oncology Department, Instituto de Investigación Sanitaria Aragón, \\ Hospital Clinico Universitario Lozano Blesa, Zaragoza, Spain; \\ ${ }^{2}$ Medical Oncology Department, Hospital Universitario Miguel Servet, Zaragoza, Spain; \\ ${ }^{3}$ Medical Oncology Department, Hospital Vall d'Hebron, Barcelona, Spain; \\ ${ }^{4}$ Medical Oncology Department, Hospital Clínic, Barcelona, Spain; \\ ${ }^{5}$ Medical Oncology Department, Hospital Puerta de Hierro, Madrid, Spain; \\ ${ }^{6}$ Medical Oncology Department, Hospital Sant Pau, Barcelona, Spain; \\ ${ }^{7}$ Medical Oncology Department, Hospital Son Llátzer, Palma de Mallorca, Spain; \\ ${ }^{8}$ Medical Oncology Department, Hospital de Mararó, Barcelona, Spain; \\ ${ }^{9}$ Medical Oncology Department, Consorcio Hospital Provincial de Castellón, Castellón De La Plana, Spain; \\ ${ }^{10}$ Medical Oncology Department, Althaia Xarxa Assistencial Universitaria de Manresa, Manresa, Spain; \\ ${ }^{11}$ Medical Oncology Department, Hospital La Paz, Madrid, Spain; \\ ${ }^{12}$ Medical Oncology Department, Hospital General de Valencia, Valencia, Spain; \\ ${ }^{13}$ Medical Oncology Department, Hospital Son Espases, Palma de Mallorca, Spain; \\ ${ }^{14}$ Medical Oncology Department, Hospital Clínico San Carlos, Madrid, Spain; \\ ${ }^{15}$ Medical Oncology Department, Hospital La Fe, Valencia, Spain; \\ ${ }^{16}$ Medical Oncology Department, Fundación Jiménez Díaz, Madrid, Spain; \\ ${ }^{17}$ Medical Oncology Department, Hospital Nuestra Señora de Valme, Sevilla, Spain; \\ ${ }^{18}$ Medical Oncology Department, Hospital Ramón y Cajal, Madrid, Spain
}

\begin{abstract}
Background: The WORLD07 project is a femalespecific database to prospectively analyze the characteristics of Spanish women with lung cancer. Patients and Methods: We analyzed and compared lung cancer features in women with and without a family history of cancer/lung cancer. Results: Two thousand and sixty women were included: 876 had a family history of cancer (lung cancer, 34\%) and 886 did not, with no significant differences between groups, except for smoking status $(p=0.036)$. We found statistically
\end{abstract}

Correspondence to: Dolores Isla, MD, Ph.D., Medical Oncology Department, Instituto de Investigación Sanitaria Aragón, Hospital Clínico Universitario Lozano Blesa, Av/ San Juan Bosco 15, 50009 Zaragoza, Spain. Tel.: +34 976765 746, Fax: +34 976354 212, email: lola.isla@gmail.com

Key Words: Cancer, lung cancer risk, Spanish women, family history, WORLD07 database, smoking, epidermal growth factor receptor, menopausal status. significant correlations between epidermal growth factor receptor (EGFR) mutation and smoking status in patients with a family history of cancer $(r=-0.211 ; p<0.001)$ and lung cancer $(r=-0.176 ; p<0.001)$. Longer median overall survival was observed in women with a family history of cancer and lung cancer. Conclusion: Among Spanish women with lung cancer, a greater proportion were current smokers in those with a family history of cancer/lung cancer. There was a significant correlation between the presence of EGFR mutation and smoking.

Globally, lung cancer still remains the leading cause of cancer death in Europe (1), with contrasting trends in mortality rates between sexes (2-5). Differences in lung cancer between women and men exist due to factors such as pathophysiology, histology, etiology, risk factors, prognosis and treatment outcomes, indicating that the disease in women is biologically different from that in men (6-11). A retrospective study conducted by the Spanish Lung Cancer Group revealed significant differences in the pathophysiological characteristics 
of lung cancer between female and male patients with advanced non-small cell lung cancer (NSCLC), and better outcomes for women compared to men (12).

Despite several studies having noted a decreasing trend in death rates from lung cancer in men, in women, lung cancer death rates continues to increase $(3,13-15)$. In fact, lung cancer was predicted to account for the highest cancer mortality rate among women in the European Union in 2015 (3). In Spanish women, the increases in lung cancer incidence and mortality have been greater than for other types of cancer, including of the colon and breast (14).

Lung cancer is frequently cited as an example of a malignancy almost exclusively attributable to environmental exposure (16). The role of family history of cancer as a potential risk factor has been the subject of numerous studies (17-22). Findings from the literature have suggested that a family history of lung cancer is a predictor of an increased risk of developing the disease $(17,20,21)$, especially in those aged less than 50 years (19). Likewise, in never-smokers, the risk of lung cancer has been shown to be increased among those with familial aggregation of lung cancer $(23,24)$. Additionally, patients with lung cancer with a first-degree relative with lung cancer have been shown to have a worse outcome than those without a family history (25).

All the above prompted the Association for Research Lung Cancer in Women (ICAPEM group) to conduct a female-specific database to prospectively analyze the characteristics of Spanish women with lung cancer in order to gain a better understanding of lung cancer in this group of patients. This is the WORLD07 project. The aim of this study was to characterize and compare the clinical, histological, and molecular features of Spanish women diagnosed with lung cancer with and without a family history of cancer or lung cancer participating in the WORLD07 project.

\section{Patients and Methods}

Design and study population. The WORLD07 project was a prospective, multicenter, female-specific epidemiologicaI study conducted in 38 Oncology-based centers across Spain, in accordance with the Declaration of Helsinki including all amendments. The study was approved by the Institutional Review Board at each hospital participating in the study, and all patients provided their written informed consent to the use of their data prior to inclusion.

All consecutive adult (aged $\geq 18$ years) women with a pathological diagnosis of lung cancer, regardless of whether they were receiving treatment for the disease, were eligible for the study.

Following routine clinical practice, patient data were prospectively gathered from both medical records and interviews conducted by trained interviewers, using a standardized questionnaire that was prepared by the ICAPEM Board. Patient data were recorded in an electronic database. The security and confidentiality of the data in the database was guaranteed.
Data collected included age, body mass index, educational level, family history of cancer (first- and second-degree relatives) and patient's previous history of cancer, race, Eastern Cooperative Oncology Group (ECOG) performance status, number of children, menopausal status (premenopausal or postmenopausal), previous hormone replacement therapy (HRT), smoking status, other lung cancer risk factors, histology, disease stage, epidermal growth factor receptor $(E G F R)$ mutational status or other molecular markers tested, age of menarche, type and duration of HRT, oral contraceptive use, lung cancer history and treatment, and survival data.

Smoking status was defined according to the Centers for Disease Control and Prevention tobacco glossary (26) as current smoker (an adult who has smoked 100 cigarettes in their lifetime and who currently smokes cigarettes), former smoker (an adult who smoked at least 100 cigarettes in their lifetime but who had quit smoking at the time of the interview) and never smoker (an adult who has never smoked, or who has smoked fewer than 100 cigarettes in their lifetime). Information on passive smoking was also recorded, defined as the breathing in of cigarette smoke from people who are smoking nearby.

Statistical analysis. Descriptive analyses were used to analyze the clinical, histological and molecular characteristics of patients. Overall survival (OS) was defined as the date from pathological diagnosis of lung cancer to death or last recorded follow-up, and was calculated using the Kaplan-Meier method to construct survival plots and the log-rank test was used to analyze differences in survival. A bivariate analysis of variables associated with family history (yes/no) as the dependent variable was conducted. Variables with statistical significance or with $p<0.25$ in the bivariate model were analyzed in a multivariate logistic regression model. Odds ratios (OR) and 95\% confidence interval (CI) were calculated for the independent predictive factors. Possible correlations between age, stage, histology, EGFR status (wild-type or mutant), and smoking or menopausal status were investigated using the Pearson correlation coefficient. Tumor biopsy samples were tested for $E G F R$ mutations (exons 18, 19, 20, and 21) using polymerase chain reaction. Significance level was set at $p<0.05$ and all statistical analyses were carried out with the Statistical Package for the Social Sciences (version 13.0; SPSS Inc., Chicago, IL, USA).

\section{Results}

Patients. From October 2007 to December 2012, a total of 2,072 women with lung cancer were recruited and followedup until December 2013. Of these, 12 women were noneligible, hence the study population comprised of 2,060 patients.

A total of $876(42.5 \%)$ women reported having a family history of cancer, among these, over half had a first-degree relative with cancer. The most common malignancies in a family member were lung $(34.7 \%)$, colon $(25.0 \%)$ and cervical $(17.6 \%)$ cancer. There were no significant differences in family history between patients with small-cell lung cancer (SCLC) and those with NSCLC (Table I).

Patient characteristics and demographics according to whether had a family history of cancer or not are shown in Table II. We found a significant difference in the proportion 
Table I. Characteristics of patients' family history of cancer.

\begin{tabular}{lccc}
\hline Characteristic & $\begin{array}{c}\text { SCLC } \\
(\mathrm{n}=285)\end{array}$ & $\begin{array}{c}\text { NSCLC } \\
(\mathrm{n}=1,775)\end{array}$ & $\begin{array}{c}\text { Total } \\
(\mathrm{N}=2,060)\end{array}$ \\
\hline Family history of cancer & & & \\
Yes & $124(43.5)$ & $752(42.4)$ & $876(42.5)$ \\
No & $132(46.3)$ & $754(42.5)$ & $886(43.0)$ \\
Missing/unknown & $29(10.2)$ & $269(15.1)$ & $298(14.5)$ \\
Relationship & & & \\
First-degree & $66(53.2)$ & $401(53.3)$ & $467(53.3)$ \\
Second-degree & $16(12.9)$ & $123(16.4)$ & $139(15.9)$ \\
First and second degree & $36(29.0$ & $192(25.5)$ & $228(26.0)$ \\
Missing/unknown & $6(4.8)$ & $36(4.8)$ & $42(4.8)$ \\
Type of cancer & & & \\
Lung & $43(34.7)$ & $261(34.7)$ & $304(34.7)$ \\
Colon & $32(25.8)$ & $187(24.9)$ & $219(25.0)$ \\
Breast & $6(4.8)$ & $31(4.1)$ & $37(4.2)$ \\
Cervical & $26(21.0)$ & $128(17.0)$ & $154(17.6)$ \\
Ovarian & $2(1.6)$ & $11(1.5)$ & $13(1.5)$ \\
Head and neck & $15(12.1)$ & $65(8.6)$ & $80(9.1)$ \\
Gastrointestinal & $20(16.1)$ & $97(12.9)$ & $117(13.4)$ \\
Endometrial & $3(2.4)$ & $14(1.9)$ & $17(1.9)$ \\
Liver & $9(7.3)$ & $56(7.4)$ & $65(7.4)$ \\
Leukemia & $3(2.4)$ & $34(4.5)$ & $37(4.2)$ \\
Pancreatic & $8(6.5)$ & $37(4.9)$ & $45(5.1)$ \\
Prostate & $6(4.8)$ & $71(9.4)$ & $77(8.8)$ \\
Kidney & $4(3.2)$ & $21(2.8)$ & $25(2.9)$ \\
CNS & $6(4.8)$ & $24(3.2)$ & $30(3.4)$ \\
Uterine & $7(5.6)$ & $18(2.4)$ & $25(2.9)$ \\
Bladder & $7(5.6)$ & $29(3.9)$ & $36(4.1)$ \\
Other & $19(15.3)$ & $105(14.0)$ & $124(14.2)$ \\
\hline & & & \\
\hline & & & \\
& & &
\end{tabular}

Data are number of patients and percentage (\%). CNS, Central nervous system; NSCLC, non-small-cell lung cancer; SCLC, small-cell lung cancer.

of patients with smoking history between both groups $(p=0.036)$. Overall, in patients without a family history of cancer, there was a higher proportion of never smokers $(43.0 \%)$ and a lower proportion of current smokers (40.5\%) than in patients with a family history of cancer $(36.4 \%$ and $47.2 \%$, respectively). Most patients in both groups were postmenopausal $(79.6 \%$ and $81.9 \%$ for patients without and with a family history of cancer, respectively) and had not received previous HRT ( $73.7 \%$ and $76.9 \%$, respectively).

There were no statistically significant differences between the groups of patients with previous history of lung cancer and those without (Table II).

Regression analyses. Logistic regression analysis showed a positive correlation between smoking status (current smoker, former smoker, and never-smoker) and family history of cancer (yes/no), indicating that smoking was associated with an increase in the 'risk' of having a family history of lung cancer $(\mathrm{OR}=1.31 ; 95 \% \mathrm{CI}=1.086-1.585 ; p=0.005)$. We found that the power of classification, specificity, and sensitivity were $53.4 \%, 59.2 \%$, and $47.5 \%$, respectively.
Subgroup correlations. In patients with a family history of cancer, EGFR mutation was significantly associated with smoking $(\mathrm{r}=-0.211 ; p<0.001)$. A similar result was obtained for smoking status between current smokers versus never smokers or former smokers $(\mathrm{r}=-0.292 ; p<0.001)$. There was no correlation between $E G F R$ mutation and menopausal status $(\mathrm{r}=0.078 ; p=0.111)$.

In patients with a family history of lung cancer, we found a significant association between EGFR mutation and smoking $(\mathrm{r}=-0.176 ; p<0.001)$. There was no correlation between EGFR mutation and menopausal status $(\mathrm{r}=0.070$; $p=0.117)$.

Survival. Median OS for the total population was $24.0(95 \%$ $\mathrm{CI}=22.1-26.0)$ months. Median OS was 23.0 (95\% CI=20.725.3) months in patients without a family history of cancer versus $25.3(95 \% \mathrm{CI}=21.9-28.8)$ months in patients with a family history of cancer $(\log$-rank $p=0.029)$ (Figure $1 \mathrm{~A})$. We found a median OS of 24.9 (95\% CI=20.8-29.0) months in patients without a family history of lung cancer versus 29.9 (95\% CI=21.7-38.0) months in patients with a family history of lung cancer $(\log -$ rank $p=0.191)$ (Figure 1B).

\section{Discussion}

To the best of our knowledge, this is the first study addressing the impact of a family history of cancer or lung cancer on a large population of women with lung cancer in Spain.

In our analysis of the WORLD07 study, we found that nearly $43 \%$ of patients had a family history of cancer, with a first-degree relative being the most frequently affected family member category in just over half of the patients. Although we did not record significant differences between patients with SCLC and those with NSCLC, our findings suggest that patients' characteristics were similar for those with a family history of cancer and those without, except for smoking status. Among those women without a family history of cancer, it was found that there was a higher proportion of patients who had never been smokers than those who were current smokers, whereas among patients with a family history of cancer, we found a lower proportion of patients who had never smoked in comparison to those who were current smokers. Although there is a lack of information regarding this correlation, the clinic-based casecontrol study conducted by Lin et al. with Chinese neversmoker patients, showed that familial aggregation of cancer or lung cancer in non-smoker patients had been shown to increase their risk of lung cancer (24).

In our series, regression analyses revealed weak correlations (albeit statistically significant) between the presence of the EGFR mutation and smoking habit in patients with both a family history of cancer and lung 
Table II. Patient characteristics and demographics according to family history of cancer and lung cancer.

\begin{tabular}{|c|c|c|c|c|}
\hline & \multicolumn{2}{|c|}{ Family history of cancer } & \multicolumn{2}{|c|}{ Family history of lung cancer } \\
\hline & No $(n=886)$ & Yes $(n=876)$ & No $(n=572)$ & Yes $(n=304)$ \\
\hline Median age (range), years & $62.1(49.9-74.3)$ & $61.1(49.5-72.7)$ & $61.2(49.9-72.8)$ & $60.7(49.2-72.2)$ \\
\hline$p$-value & \multicolumn{2}{|c|}{0.063} & \multicolumn{2}{|c|}{0.489} \\
\hline \multicolumn{5}{|l|}{ Smoking history } \\
\hline Never smoker & $381(43.0)$ & $319(36.4)$ & $218(38.1)$ & $101(33.2)$ \\
\hline Former smoker & $139(15.7)$ & $137(15.6)$ & $98(17.1)$ & $39(12.8)$ \\
\hline Current smoker & $359(40.5)$ & $413(47.2)$ & $252(44.1)$ & $161(53.0)$ \\
\hline Missing/unknown & $7(0.8)$ & $7(0.8)$ & $4(0.7)$ & $3(1.0)$ \\
\hline$p$-value & \multicolumn{2}{|c|}{0.036} & \multicolumn{2}{|c|}{0.066} \\
\hline \multicolumn{5}{|l|}{ Histology } \\
\hline SCLC & $132(14.9)$ & $124(14.2)$ & $81(14.2)$ & $43(14.1)$ \\
\hline NSCLC & $754(85.1)$ & $752(85.8)$ & $491(85.8)$ & $261(85.9)$ \\
\hline Adenocarcinoma & $548(72.7)$ & $532(70.7)$ & $352(71.7)$ & $180(69.0)$ \\
\hline Bronchioloalveolar cancer & $31(4.1)$ & $32(4.3)$ & $17(3.5)$ & $15(5.7)$ \\
\hline Squamous cell carcinoma & $79(10.5)$ & $89(11.8)$ & $55(11.2)$ & $34(13.0)$ \\
\hline Large cell carcinoma & $43(5.7)$ & $51(6.8)$ & $35(7.1)$ & $16(6.1)$ \\
\hline Other & $27(3.6)$ & $31(4.1)$ & $22(4.5)$ & $9(3.5)$ \\
\hline Missing/unknown & $26(3.4)$ & $17(2.3)$ & $10(2.0)$ & $7(2.7)$ \\
\hline$p$-value & \multicolumn{2}{|c|}{0.685} & \multicolumn{2}{|c|}{0.512} \\
\hline \multicolumn{5}{|c|}{ NSCLC: TNM classification at diagnosis } \\
\hline I & $89(11.8)$ & $91(12.1)$ & $65(13.2)$ & $26(10.0)$ \\
\hline II & $36(4.8)$ & $41(5.5)$ & $29(5.9)$ & $12(4.6)$ \\
\hline IIIA & $67(8.9)$ & $82(10.9)$ & $57(11.6)$ & $25(9.6)$ \\
\hline IIIB resectable & $26(3.4)$ & $23(3.0)$ & $11(2.2)$ & $12(4.6)$ \\
\hline IIIB unresectable & $66(8.8)$ & $85(11.3)$ & $56(11.4)$ & $29(11.1)$ \\
\hline IV & $458(60.7)$ & $420(55.9)$ & $268(54.6)$ & $152(58.2)$ \\
\hline Missing/unknown & $12(1.6)$ & $10(1.3)$ & $5(1.0)$ & $5(1.9)$ \\
\hline$p$-value & \multicolumn{2}{|c|}{0.446} & \multicolumn{2}{|c|}{0.343} \\
\hline \multicolumn{5}{|l|}{ SCLC stage } \\
\hline Limited & $61(46.2)$ & $58(46.8)$ & $36(44.4)$ & $22(51.2)$ \\
\hline Extensive & $67(50.8)$ & $65(52.4)$ & $44(54.3)$ & $21(48.8)$ \\
\hline Missing/unknown & $4(3.0)$ & $1(0.8)$ & $1(1.2)$ & 0 \\
\hline$p$-value & \multicolumn{2}{|c|}{1.000} & \multicolumn{2}{|c|}{0.428} \\
\hline \multicolumn{5}{|l|}{$E G F R$ status } \\
\hline Number of patients tested & 410 & 420 & 276 & 144 \\
\hline Mutated & $139(33.9)$ & $142(33.8)$ & $91(33.0)$ & $51(35.4)$ \\
\hline Wild-type & $271(66.1)$ & $278(66.2)$ & $185(67.0)$ & $93(64.6)$ \\
\hline$p$-value & \multicolumn{2}{|c|}{1.000} & \multicolumn{2}{|c|}{0.664} \\
\hline \multicolumn{5}{|l|}{ Menopausal status } \\
\hline Premenopausal & $129(14.5)$ & $123(14.0)$ & $75(13.1)$ & $48(15.8)$ \\
\hline Postmenopausal & 705 (79.6) & $717(81.9)$ & $474(82.9)$ & $243(79.9)$ \\
\hline Missing/unknown & $52(5.9)$ & $36(4.1)$ & $23(4.0)$ & $13(4.3)$ \\
\hline$p$-value & 0.241 & 0.605 & & \\
\hline \multicolumn{5}{|l|}{ Previous HRT } \\
\hline Yes & $49(5.5)$ & $70(8.0)$ & $46(8.0)$ & $24(7.9)$ \\
\hline No & $653(73.7)$ & $674(76.9)$ & $445(77.8)$ & $229(75.3)$ \\
\hline Missing/unknown & $184(20.8)$ & $132(15.1)$ & $81(14.2)$ & $51(16.8)$ \\
\hline$p$-value & \multicolumn{2}{|c|}{0.002} & & \\
\hline
\end{tabular}

Data are number of patients (\%), unless otherwise indicated. EGFR, epidermal growth factor receptor gene; HRT, hormone replacement therapy; NSCLC, non-small cell lung cancer; SCLC, small-cell lung cancer.

cancer, whereas no correlation between EGFR mutation and menopausal status was achieved, irrespective of the type of familial aggregation of cancer. However, our results are not concordant with previous literature. Studies including both sexes have shown a link between a family history of lung cancer and EGFR mutation in patients with NSCLC (27) and in patients with NSCLC who have never smoked (2729). Smoking status is related to family history due to social 

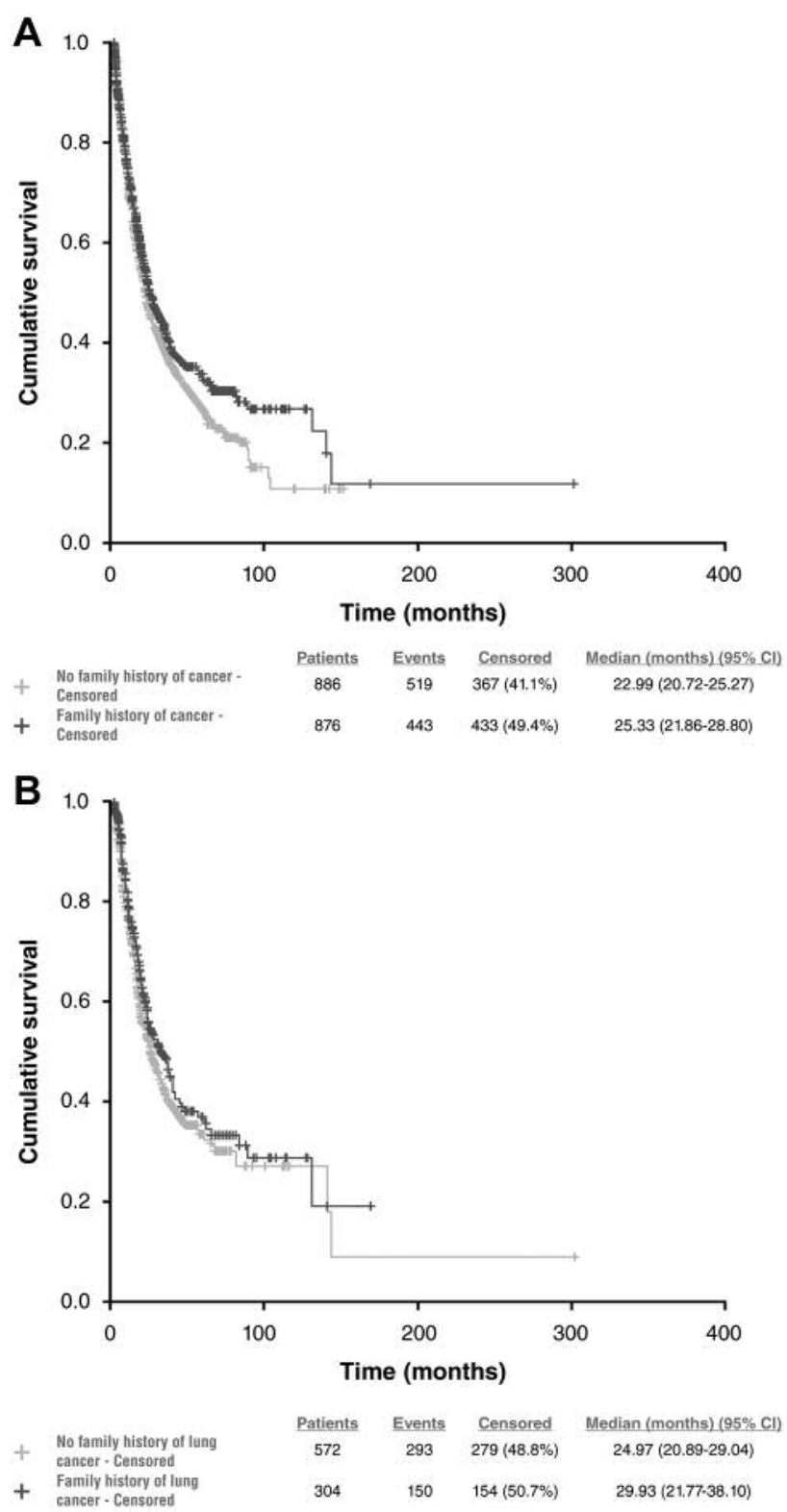

Figure 1. Kaplan-Meier survival plots for overall survival stratified according to family history of cancer (A) and lung cancer $(B)$.

reasons and tumors harboring EGFR mutations (28). Possible reasons for the different results found in our series are that fewer than half of the eligible patients had been tested for $E G F R$ status, and there was a high incidence of passive smokers (nearly 15\%). Besides the different geographical locations, genetics and environmental or lifestyle factors, there are possible etiological factors for lung cancer in never-smokers that could partly explain our results (30). An important point regarding our results in women with lung cancer and a family history of cancer who were current smokers is that cancer risk is heavily influenced by extrinsic factors, in addition to the accumulation of endogenous mutations by intrinsic processes (31).

It would have been interesting to know the smoking history of those families with a past history of cancer or lung cancer, in order to investigate the possible links with passive exposure to tobacco smoke or the inducement to smoke in the WORLD07 population. Nonetheless, this analysis could still be addressed in the future.

Overall, when comparing the median OS of patients, we found that those without a family history of cancer or lung cancer presented a slightly shorter OS than those with a family history, although these differences only achieved statistical significance among those patients with and without a family history of cancer. Li et al. reported that patients with NSCLC and a family history of lung cancer had improved survival compared to patients without such history, but only at early stages of the disease (32). However, no difference was found between patients with or without a family history of cancer. In contrast, Ganti et al. reported that median survival in patients with a family history of lung cancer was lower than in patients without a family history (52 vs. 58 months) (25). It is not clear why in the WORLD07 population the OS was longer in patients with a family history of cancer or lung cancer, and there are insufficient data in the literature to draw any definite conclusions. A possible explanation could be that there are many biological subtypes of lung cancer in women associated with family history that are linked to genetic differences but also lifestyle/environmental factors $(33,34)$.

Some limitations to this study need to be highlighted when interpreting the results. Firstly, the actual study comprised a female cohort of patients with lung cancer. Therefore including a male cohort would have added important information by allowing comparisons between the sexes, revealing conclusions of differences between both sexes. Secondly, the poor specificity and sensitivity found in the regression analyses mean that it is difficult to reach any firm conclusions. Thirdly, despite the fact that this was a prospective epidemiological study, there was a high rate of missing or unknown data, which could have affected the results for some of the outcomes.

Despite all these limitations, our study does have strengths. These comprise the prospective design, the high number of patients included from all regions in Spain, and the inclusion of a large amount of epidemiological, clinical, molecular, and therapeutic data used to investigate potential differences between women with a family history of cancer versus those without. It would have been very interesting to know the clinical characteristics of other populations of women with lung cancer and a family history of cancer in order to compare our data. 
In conclusion, this analysis shows that in Spanish women with lung cancer, there were a greater proportion of current smokers in those with a family history of cancer or lung cancer in comparison to those without. There was a significant correlation between the presence of EGFR mutation and smoking habit. In addition, OS was longer in patients who had a family history of cancer or lung cancer than that found for the overall population.

\section{Acknowledgements}

The Authors would like to thank all the patients and their families who participated in this study. They also thank Ana LópezBallesteros and Antonio Torres-Ruiz at Dynamic Science S.L.) for their editorial support and Maria Luz Amador for her help.

\section{References}

1 Ferlay J, Soerjomataram I, Dikshit R, Eser S, Mathers C, Rebelo M, Parkin DM, Forman D and Bray F: Cancer incidence and mortality worldwide: Sources, methods and major patterns in globocan 2012. Int J Cancer 136(5): E359-386, 2015.

2 Ferlay J, Steliarova-Foucher E, Lortet-Tieulent J, Rosso S, Coebergh JW, Comber H, Forman D and Bray F: Cancer incidence and mortality patterns in europe: Estimates for 40 countries in 2012. Eur J Cancer 49(6): 1374-1403, 2013.

3 Malvezzi M, Bertuccio P, Rosso T, Rota M, Levi F, La Vecchia $\mathrm{C}$ and Negri E: European cancer mortality predictions for the year 2015: Does lung cancer have the highest death rate in eu women? Ann Oncol 26(4): 779-786, 2015.

4 Siegel RL, Miller KD and Jemal A: Cancer statistics, 2015. CA Cancer J Clin 65(1): 5-29, 2015.

5 Torre LA, Bray F, Siegel RL, Ferlay J, Lortet-Tieulent J and Jemal A: Global cancer statistics, 2012. CA Cancer J Clin 65(2): 87-108, 2015.

6 Alberg AJ, Wallace K, Silvestri GA and Brock MV: Invited commentary: The etiology of lung cancer in men compared with women. Am J Epidemiol 177(7): 613-616, 2013.

7 Kligerman S and White C: Epidemiology of lung cancer in women: Risk factors, survival, and screening. AJR Am J Roentgenol 196(2): 287-295, 2011.

8 Nakamura H, Ando K, Shinmyo T, Morita K, Mochizuki A, Kurimoto $\mathrm{N}$ and Tatsunami S: Female gender is an independent prognostic factor in non-small-cell lung cancer: A meta-analysis. Ann Thorac Cardiovasc Surg 17(5): 469-480, 2011.

9 North CM and Christiani DC: Women and lung cancer: What is new? Semin Thorac Cardiovasc Surg 25(2): 87-94, 2013.

10 Otsuka S, Klimowicz AC, Kopciuk K, Petrillo SK, Konno M, Hao D, Muzik H, Stolte E, Boland W, Morris D, Magliocco AM and Bebb DG: Cxcr4 overexpression is associated with poor outcome in females diagnosed with stage IV non-small cell lung cancer. J Thorac Oncol 6(7): 1169-1178, 2011.

11 Rivera MP: Lung cancer in women: Differences in epidemiology, biology, histology, and treatment outcomes. Semin Respir Crit Care Med 34(6): 792-801, 2013.

12 Isla D FE, Garrido P, Viñolas N, Lianes P, Garcia-Campelo R et al: Women with advanced non-small cell lung cancer participating in first-line Spanish Lung Cancer Group (SLCG) trials. Analysis of characteristics and treatment outcomes compared to men. Ann Oncol 17(Suppl 9): ix218 [Abstr 727PD], 2006.

13 Bray FI and Weiderpass E: Lung cancer mortality trends in 36 European countries: Secular trends and birth cohort patterns by sex and region 1970-2007. Int J Cancer 126(6): 1454-1466, 2010.

14 Remon J, Molina-Montes E, Majem M, Lianes P, Isla D, Garrido P, Felip E, Vinolas N, de Castro J, Artal A and Sanchez MJ: Lung cancer in women: An overview with special focus on Spanish women. Clin Transl Oncol 16(6): 517-528, 2014.

15 Torre LA, Siegel RL, Ward EM and Jemal A: International variation in lung cancer mortality rates and trends among women. Cancer Epidemiol Biomarkers Prev 23(6): 1025-1036, 2014.

16 Air pollution and cancer (2013). Available at https://www.iarc.fr/en/ publications/books/sp161/AirPollutionandCancer161.pdf.

17 Cassidy A, Balsan J, Vesin A, Wu X, Liloglou T, Brambilla C, Timsit JF and Field JK: Cancer diagnosis in first-degree relatives and non-small cell lung cancer risk: Results from a multi-centre case-control study in Europe. Eur J Cancer 45(17): 3047-3053, 2009.

18 Cote ML, Liu M, Bonassi S, Neri M, Schwartz AG, Christiani DC, Spitz MR, Muscat JE, Rennert G, Aben KK, Andrew AS, Bencko V, Bickeboller H, Boffetta P, Brennan P, Brenner H, Duell EJ, Fabianova E, Field JK, Foretova L, Friis S, Harris CC, Holcatova I, Hong YC, Isla D, Janout V, Kiemeney LA, Kiyohara C, Lan Q, Lazarus P, Lissowska J, Le Marchand L, Mates D, Matsuo K, Mayordomo JI, McLaughlin JR, Morgenstern H, Mueller H, Orlow I, Park BJ, Pinchev M, Raji OY, Rennert HS, Rudnai P, Seow A, Stucker I, SzeszeniaDabrowska N, Dawn Teare M, Tjonnelan A, Ugolini D, van der Heijden HF, Wichmann E, Wiencke JK, Woll PJ, Yang P, Zaridze D, Zhang ZF, Etzel CJ and Hung RJ: Increased risk of lung cancer in individuals with a family history of the disease: A pooled analysis from the International Lung Cancer Consortium. Eur J Cancer 48(13): 1957-1968, 2012.

19 Lissowska J, Foretova L, Dabek J, Zaridze D, SzeszeniaDabrowska N, Rudnai P, Fabianova E, Cassidy A, Mates D, Bencko V, Janout V, Hung RJ, Brennan P and Boffetta P: Family history and lung cancer risk: International multicentre casecontrol study in Eastern and Central Europe and meta-analyses. Cancer Causes Control 21(7): 1091-1104, 2010.

20 Matakidou A, Eisen T and Houlston RS: Systematic review of the relationship between family history and lung cancer risk. $\mathrm{Br}$ J Cancer 93(7): 825-833, 2005.

21 Rachtan J, Sokolowski A, Niepsuj S, Zemla B and Zwierko M: Familial lung cancer risk among women in Poland. Lung Cancer 65(2): 138-143, 2009.

22 Zhang Y, Shu XO, Gao YT, Ji BT, Yang G, Li HL, Kilfoy B, Rothman N, Zheng W and Chow WH: Family history of cancer and risk of lung cancer among nonsmoking Chinese women. Cancer Epidemiol Biomarkers Prev 16(11): 24322435, 2007.

23 Brenner DR, Hung RJ, Tsao MS, Shepherd FA, Johnston MR, Narod S, Rubenstein W and McLaughlin JR: Lung cancer risk in never-smokers: A population-based case-control study of epidemiologic risk factors. BMC Cancer 10: 285, 2010.

24 Lin H, Huang YS, Yan HH, Yang XN, Zhong WZ, Ye HW, Yang JJ, Zhou Q and Wu YL: A family history of cancer and lung cancer risk in never-smokers: A clinic-based case-control study. Lung Cancer 89(2): 94-98, 2015. 
25 Ganti AK, Loberiza FR Jr. and Kessinger A: Association of positive family history with survival of patients with lung cancer. Lung Cancer 63(1): 136-139, 2009.

26 State-specific secondhand smoke exposure and current cigarette smoking among adults - United States, 2008. MMWR Morb Mortal Wkly Rep 58(44): 1232-1235, 2009.

27 He Y, Li S, Ren S, Cai W, Li X, Zhao C, Li J, Chen X, Gao G, Li W, Zhou F and Zhou C: Impact of family history of cancer on the incidence of mutation in epidermal growth factor receptor gene in non-small cell lung cancer patients. Lung Cancer 81(2): 162-166, 2013.

28 Gaughan EM, Cryer SK, Yeap BY, Jackman DM and Costa DB: Family history of lung cancer in never smokers with non-smallcell lung cancer and its association with tumors harboring $E G F R$ mutations. Lung Cancer 79(3): 193-197, 2013.

29 Gazdar A, Robinson L, Oliver D, Xing C, Travis WD, Soh J, Toyooka S, Watumull L, Xie Y, Kernstine K and Schiller JH: Hereditary lung cancer syndrome targets never smokers with germline EGFR gene t790m mutations. J Thorac Oncol 9(4): 456-463, 2014

30 Toh CK and Lim WT: Lung cancer in never-smokers. J Clin Pathol 60(4): 337-340, 2007.

$31 \mathrm{Wu}$ S, Powers S, Zhu W and Hannun YA: Substantial contribution of extrinsic risk factors to cancer development. Nature 529(7584): 43-47, 2016
32 Li N, Shao K, Chen Z, Qiu B, Wang Z, Tan F, Wang J, Tan X, Li B, Xiong M, Zhou F and He J: The impact of positive cancer family history on the clinical features and outcome of patients with non-small cell lung cancer. Fam Cancer 10(2): 331-336, 2011.

33 Couraud S, Souquet PJ, Paris C, Do P, Doubre H, Pichon E, Dixmier A, Monnet I, Etienne-Mastroianni B, Vincent M, Tredaniel J, Perrichon M, Foucher P, Coudert B, Moro-Sibilot D, Dansin E, Labonne S, Missy P, Morin F, Blanche H and Zalcman G: BIOCAST/IFCT-1002: Epidemiological and molecular features of lung cancer in never-smokers. Eur Respir J 45(5): 1403-1414, 2015.

34 Jayes L, Haslam PL, Gratziou CG, Powell P, Britton J, Vardavas C, Jimenez-Ruiz C and Leonardi-Bee J: Smokehaz: Systematic reviews and meta-analyses of the effects of smoking on respiratory health. Chest 150(1): 164-179, 2016.

Received October 14, 2016

Revised November 7, 2016

Accepted November 8, 2016 